\title{
Amounts of Alcohol and Carbon Dioxide Produced in the Anaerobic Respiration of Seeds of Nelumbo nucifera and Others
}

\author{
by Kiyonobu TOYODA*
}

Received April 9, 1970

\begin{abstract}
No alcohol was detected in new and old seeds of Nelumbo, while old seeds contained small amounts of alcohol in three other species. Seeds of Nelumbo, rice and wheat were incubated at $35^{\circ}$ in syringes filled with boiled distilled water, and the amounts of alcohol and $\mathrm{CO}_{2}$ produced were measured. Nelumbo seed showed more active metabolism than the other two. The total amount of $\mathrm{CO}_{2}$ produced was more than the theoretical amount to be expected from the usual alcoholic fermentation. These facts may be mainly due to the previous observation that some redox substances participate in the anaerobic respiration.
\end{abstract}

On the anaerobic respiration of the seed of Nelumbo nucifera, the writer ${ }^{1,22}$ has studied previously. Under anaerobic conditions seed may produce ethanol and $\mathrm{CO}_{2}$ through alcoholic fermentation of endogenous hexose. Numerous papers ${ }^{3-9)}$ have been presented concerning the respiration in germinating seeds of higher plants. However, the relation between the amounts of ethanol and $\mathrm{CO}_{2}$ produced has not yet been satisfactorily elucidated. The present study deals with the amounts of ethanol and $\mathrm{CO}_{2}$ produced during the anaerobic respiration of Nelumbo, rice and wheat.

\section{Material and Methods}

The sample mainly used in this work was one year-old Nelumbo fruit collected at Kamakura. The fruit-coat was peeled off and the seed was soaked in an Usuplun solution $(0.5 \%)$. After $1 \mathrm{hr}$. seed coat was removed and the naked seed was treated with a new Usuplun solution for $10 \mathrm{~min}$., followed by washing throughly with boiled distilled water. Each of the sterilized Nelumbo seeds was put in a syringe $(30 \mathrm{~m} l$ capacity) which had been filled with $20 \mathrm{~m} l$ boiled distilled water. Grease was applied beforehand between the piston and cylinder of the syringe, whose opening end was fitted with a rubber cap. A small amount of gas remaining between the cotyledons was removed by pulling the piston, then the gas was thoroughly excluded from the syringe. And the seeds were incubated at $35^{\circ}$ in the dark.

In all the procedure care was taken to keep off microbial contamination. At the end of each experiment, microbial contamination of the medium was examined by pouring $1 \mathrm{ml}$ of it on agar plates containing $5 \%$ glucose; the colonies formed were counted after $24 \mathrm{hr}$. incubation at $27^{\circ}$. In almost all incubation media with seeds of Nelumbo, rice or wheat, no excess counts were found beyond the level of the

\footnotetext{
* Biological Laboratory, Kanagawa Dental College, Inaoka-cho, Yokosuka, Japan.
} 
control with fresh boiled water. In cases, where a slight turbidity was noticed in incubation meduim, the data were discarded.

Experiments on the seeds of rice (Orya sativa) and wheat (Triticum aestivum) were conducted in the same way as in the above. The former were collected from a field at Kamakura, and the latter at Yokohama. Each syringe contained $780 \mathrm{mg}$ seeds (roughly corresponding to the dry weight of one Nelumbo seed).

Volume of the gas formed in a syringe was read. When it was too small to be read, it was estimated by comparing with air bubbles of known volumes contained in other syringes. It was confirmed in the previous study ${ }^{2}$ that the gas evolved from Nelumbo seeds during incubation under similar anaerobic conditions consists of $\mathrm{CO}_{2}$ at least $92 \%$. The liquid medium in the syringe was poured out, the seed being washed and incubated further boiled distilled water. To the medium taken out baryta water was added. Precipitate of $\mathrm{BaCO}_{3}$ was collected by centrifugation and weighed after drying as usual. The total amount of $\mathrm{CO}_{2}$ thus assayed was represented as the volume under standard conditions.

The supernatant fluid was distillated and alcohol was determined by colorimetric method $^{10-14)}$ by using ceric ammonium nitrate. Since the alcohols other than ethanol also react with this reagent, gas chromatography ${ }^{14)}$ was applied to the distillate to confirm that no other alcohols than ethanol was contained. The incubation medium was extracted by a mixture of ether-pentane $(2: 1, \mathrm{v} / \mathrm{v})$ for $40 \mathrm{hrs}$., and the extract was washəd with $5 \% \mathrm{HCl}$ and $10 \% \mathrm{Na}_{2} \mathrm{CO}_{3}$ solutions successively, followed by drying with anhydrous sodium sulfate. After evaporation of the soluents, the residue was subjected to gas chromatography using TEA (Triethanolamine) for packing and $\mathrm{N}_{2}$ as carrier gas.

The theoretical amount of $\mathrm{CO}_{2}$ to be produced on alcoholic fermentation was calculated according to the equation: $\mathrm{C}_{6} \mathrm{H}_{12} \mathrm{O}_{6}=2 \mathrm{C}_{2} \mathrm{H}_{4} \mathrm{OH}+2 \mathrm{CO}_{2}$.

\section{Results}

Alcohol content of freshly harvested and older seeds of some angiosperms is shown in Table 1.

Table 1. Alcohol content of new and older seeds ( $\mathrm{mg} / \mathrm{g}$ fresh $\mathrm{wt}$.).

\begin{tabular}{lcc}
\hline & Newly harvested seeds & Older seeds (age) \\
Nelumbo nucifera (Indian lotus) & 0 & $0(1$ year) \\
Oryza sativa (rice) & 0 & $0(4$ years) \\
Triticum oestivum (wheat) & 0 & 3.7 ( 7 months) \\
Glycine Max (soybean) & 0 & 0.06 (10 months) \\
\hline
\end{tabular}

Seeds of Nelumbo, rice and wheat were bottled up in syringes together with boiled distilled water and incubated for 3 days at $35^{\circ}$. Total amount of $\mathrm{CO}_{2}$ produced in 3 days was measured and the amount of $\mathrm{CO}_{2}$ corresponding to the alcohol formed was also determined. The results are shown in Table 2.

During the incubation for 3 days, most of Nelumbo seeds germinated and expanded their cotyledons and ca. $40 \%$ of rice grains swelled to germinate, while wheat seeds remained almost unchanged. 
Table 2. $\mathrm{CO}_{2}$ produced from seeds of Nelumbo, rice and wheat anaerobically incubated in water at $35^{\circ}$ for 3 days.

\begin{tabular}{lcccc}
\hline & $\begin{array}{c}\mathrm{CO}_{2} \text {-gas } \\
\text { evolved }(\mathrm{m} l)\end{array}$ & $\begin{array}{c}\mathrm{CO}_{2} \text { dissolved } \\
\text { in water }(\mathrm{m} l)\end{array}$ & $\begin{array}{c}\text { Total } \mathrm{CO}_{2} \\
(\mathrm{~m} l)\end{array}$ & $\begin{array}{c}\mathrm{CO}_{2} \text { calculated from } \\
\text { alcohol produced }(\mathrm{m} l)\end{array}$ \\
\hline Nelumbo nucifera & 6.6 & 5.2 & 1.1 .8 & 8.1 \\
Rice & 0 & 5.8 & 5.8 & 3.8 \\
Wheat & 0 & 2.8 & 2.8 & 0 \\
\hline
\end{tabular}

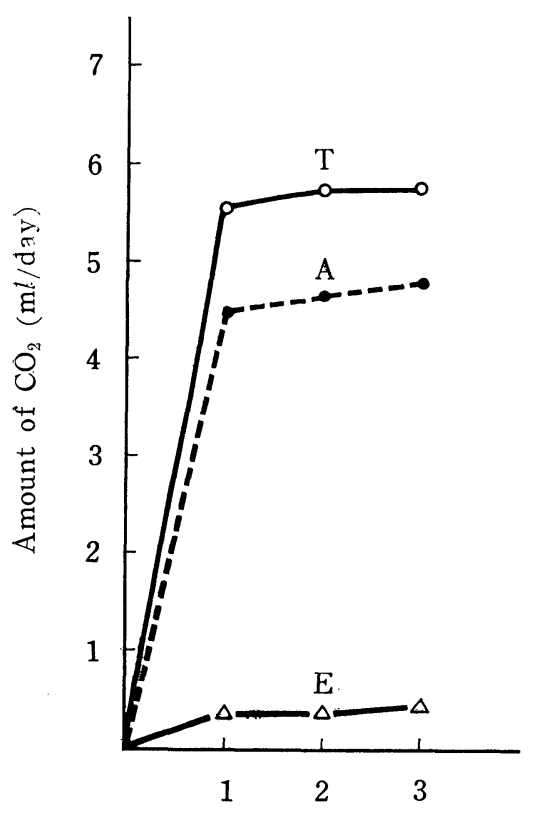

(Days)
Fig. 1. Daily production of $\mathrm{CO}_{2}$ from Nelumbo seed incubated at $35^{\circ}$ in a syringe filled with boiled distilled water.

E : $\mathrm{CO}_{2}$-gas evolved; $\mathrm{T}$ : Total $\mathrm{CO}_{2} ; \mathrm{A}$ : Theoretical amount of $\mathrm{CO}_{2}$ calculated from the amount of ethanol formed.

In another experiment, Nelumbo seeds were incubated in the same way as mentioned above, and $\mathrm{CO}_{2}$ and alcohol were measured every day, incubation water being renewed every time. The results are shown in Fig. 1, in which $E$ is the amount of $\mathrm{CO}_{2}$ as gas bubbles and $\mathrm{T}$ denotes the total $\mathrm{CO}_{2}$, gaseous plus liquid. A is the theoretical amount of $\mathrm{CO}_{2}$ calculated from the amount of ethanol formed, assuming the substrate of alcoholic fermentation as hexose.

The daily production of $\mathrm{CO}_{2}$ as represented in Fig. 1 was summed up for 3 days and was expressed in $\mathrm{mg}$ for the purpose of comparing with the decrease in the dry weight of seed during the same period. The results are shown in Table 3.

The results of gas chromatographic analysis are represented in Table 4. Evidently, no alcohol other than ehtanol was detected in the incubation medium of Nelumbo seed.

Table 3. Dry weight of Nelumbo seed before and after experiments, and production of $\mathrm{CO}_{2}$ and ethanol during 3 days' incubation.

\begin{tabular}{ccccc}
\hline $\begin{array}{c}\text { Dry weight of seed } \\
\text { before exp. (mg) }\end{array}$ & $\begin{array}{c}\text { Dry weight } \\
\text { after exp. (mg) }\end{array}$ & $\begin{array}{c}\mathrm{CO}_{2} \text { evolved } \\
\text { as gas (mg) }\end{array}$ & $\begin{array}{c}\mathrm{CO}_{2} \text { dissolved in } \\
\text { liquid phase (mg) }\end{array}$ & $\begin{array}{c}\text { Ethanol pro- } \\
\text { duced }\end{array}(\mathrm{mg})$ \\
\hline 640 & 530 & 1.9 & 33.4 & 28.4 \\
\hline
\end{tabular}


Table 4. Gas chromatographic analysis of alcohols (p. p. m.) in incubation medium of Nelumbo seed.

\begin{tabular}{lcc} 
& After 1 day & After 3 days \\
\hline Methanol & - & - \\
Ethanol & 212.5 & 342.0 \\
$i$ so-Propanol & - & - \\
$n$-Propanol & - & - \\
$i$ so-Butanol & - & trace* \\
$n$-Butanol & - & - \\
$i$ so-Amyl alcohol & - & trace* \\
$n$-Amyl alcohol & - & -
\end{tabular}

* The estimate being less than $0.001 \mathrm{ppm}$.

\section{Discussion}

Alcohol was not found in fresh seeds of four species of angiosperms examined, but small amounts of alcohol were detected in older ones. In Nelumbo seed, however, no measurable amount of alcohol was found in 1 or even in 4 year-old ones. When incubated anaerobically in water, Nelumbo seed produced more alcohol than rice and wheat seeds. $\mathrm{CO}_{2}$ production also was much more with Nelumbo seed than others. Generally the amount of $\mathrm{CO}_{2}$ produced was larger than that to be theoretically expected from the amount of alcohol produced by alcoholic fermentation (Table 2 and Fig. 1). This disagreement seems to be due to the production of $\mathrm{CO}_{2}$ from some endogenous substances or secondary consumption of ethanol by the seed.

In the previous paper, ${ }^{1)}$ the writer reported that Nelumbo seeds contained dehydroascorbic acid (about $1.6 \mathrm{mg} / \mathrm{seed}$ ), which showed a marked decrease in amount upon germination resulting in a simultaneous increase in ascorbic acid. Besides, it was found that oxidized glutathione ${ }^{16)}$ (about $1 \mathrm{mg} / \mathrm{seed}$ ) was also contained in Nelumbo seed and that this decreased upon germination giving rise to an increase in its reduced form. By these reactions, substrates may be oxidized under an anaerobic condition. But the amounts of these redox substances are too small to account for the excess of $\mathrm{CO}_{2}$ observed, some other sources seem to be responsible for this reaction.

Taylor $^{\text {ij }}$ has pointed out that in the fermentation of rice and wheat seeds the quotient $\mathrm{C}_{2} \mathrm{H}_{5} \mathrm{OH} / \mathrm{CO}_{2}$ is not always to 1 , probably due to other type of fermentation.

As seen in Tale 3 the amount of $\mathrm{CO}_{2}$ and ethanol produced was less than the dry weight decrease. This discrepancy may be elucidated by the fact the soluble substances diffused out of the seed into sorrounding water as Erigin ${ }^{6)}$ demonstrated $^{2}$ in the germination of rice and wheat.

The writer wishes to express his sincere gratitude to Professor Nagase and Mr. Koizumi of the Tokyo University of Agriculture for the operation of gas chromatography.

\section{References}

1) Toyoda, K., Bot. Mag. Tokyo 73: 98 (1960).

2) $\longrightarrow$, ibid. $76: 41$ (1963).

3) Morinaga, T., Amer. Jour. Bot. 13: 126
(1926).

4) Nakajima, Y., Bot. Mag. Tokyo 42: 576 (1928).

5) Okada, Y., Sci. Reports Tohoku Imp. 
Uni. 4th. Ser. Bil. 5: 41 (1930).

6) Erigin, P.S., Plant Physiol. $11: 821$ (1936).

7) Taylor, D. L., Amer. Jour. Bot. 29: 721 (1942).

8) Kumada, H., J. Biochem. $40: 439$ (1953).

9) Oota, Y., Yamamoto, Y. and Fujii, R., J. Biochem. $40: 187$ (1.953).

10) Duke, F.R. and Smith, F., Ind. Eng. Chem. Anal. Ed. 12: 201 (1940).

11) Elving, P.J. and Worshowsky, B., Anal.
Chem. 19: 1006 (1947).

12) Reid, V. W. and Truelove, R. K. Analyst $77: 325$ (1952).

13) - and Salmon, D. G., ibid. $80: 706$ (1955).

14) Cheronis, N. D., Organic Functional Group Analysis, Interscience Publishers (1964).

15) Ishigaki, R. and Nagase, I., Nippon Jozo Kyokai Zasshi 59: 507 (1964).

16) Toyoda, K., Bot. Mag. Tokyo $78: 443$ (1965). 